\title{
Impact Review Analysis \& Scope of Noise Pollution for Energy Harvesting
}

\author{
Arunesh Kumar Singh*, Shahida Khatoon*, Kriti*and Abhinav Saxena** \\ *Department of Electrical Engineering, Jamia Millia Islamia, New Delhi, India \\ **Department of Electrical Engineering, JSS Academy of Technical Education, Noida, U.P, India \\ Corresponding Author : tripathikriti@gmail.com
}

\begin{abstract}
Process of obtaining energy from the environment can be called as energy scavenging or energy harvesting. In this paper, we explore the scope of scavenging electrical energy from the noise pollution present in environment and review various energy harvesting techniques for this purpose. Basically, noise is an unwanted sound that is loud, unpleasant and unexpected. Very high population, industrial, commercial activities and transportation increase the noise pollution level in the environment. In urban areas, transport related noise is the major cause of noise pollution. We know that electricity requirement is increasing day by day. Clean energy resources can help the electricity grid to fulfill the increased requirement without bad consequences. Clean energy does not produce any waste, which can pollute the environment. The various mathematical expressions have shown to minimize the level of noise pollution. With help of empirical formula more electricity can be produced. We reviewed the impact of transportation noise pollution, avoidance methods and simultaneous opportunity to transform it into electrical energy.
\end{abstract}

Keywords:Energy; Environment; Noise pollution; Energy harvesting; Clean enegy; Transportation noise

\section{INTRODUCTION}

In current scenario, noise pollution is increasing rapidly. Increase in the number of vehicles moving on roads is creating more noise specifically in urban areas. The High power machines are used in heavy industries so the sound of machines in these industries creates noise pollution in the surrounding where these industries are established. Rapid increase in the use of machines such as vehicles, home appliances, electronic gadgets etc. is the cause of stress, sleeping disorder, depression and other psychiatrist problems. Robert Koch, A German bacteriologist and Nobel Prize Winner Robert Koch once said "A day will come man will have to fight merciless noise as the worst enemy of health"[Chauhan et al., 2010].

\section{LITERATURE REVIEW}

In reference to the sound signals, Frequency is the amount of air pressure change which is measured in hertz $(\mathrm{Hz})$ whereas the measure of loudness (measured in $\mathrm{dB}$ ) is the change in air pressure resulted from vibrating an object. Larger vibrations lead to the louder sound, called high amplitude and high frequency results in high pitch of sound. Road side traffic noise frequencies commonly range between $700 \mathrm{~Hz}$ to $1300 \mathrm{~Hz}$ but generally it is considered as $1000 \mathrm{~Hz}$ for simplicity[Nguyen et al., 2017]. For the measurement of noise pollution, commonly sound pressure level (SPL) meter is used[Kumar and Kumar, 2018]. Sound pressure level generally denoted as Lp(A) or Leq(A) 
where A represents A- weighted filter scheme used in SPL meter. There are three types of frequency weighting schemes named as A, C and Z weighting. In most of the countries A- weighted frequency scheme is used for noise measurement[Kjellberg et al., 1997]. Frequency response of A- weighted filter is similar to the human ear as the lower and upper cut off frequencies of A - weighted scheme are the frequencies that a human cannot hear.

Sound pressure level (SPL) is measured in decibel (dB) and is shown in Equation (1)

$$
\mathrm{SPL}=20 \log 10\left(\mathrm{P} / \mathrm{P}_{\text {ref }}\right)
$$

Where $\mathrm{P}=$ Root mean square $(\mathrm{RMS})$ pressure, And $\mathrm{P}_{\text {ref }}=$ Reference RMS pressure, at $1000 \mathrm{~Hz}$ sound frequency, it is given by Pref $=0.00002 \mathrm{~Pa}$.

Table 1. Typical relationship between Sound Pressure and SPL

\begin{tabular}{|c|c|c|}
\hline S. No. & Sound Pressure (in Pa) & SPL (in dB) \\
\hline 1 & 0.2 & 80 \\
\hline 2 & 1 & 94 \\
\hline 3 & 2 & 100 \\
\hline 4 & 10 & 114 \\
\hline 5 & 100 & 134 \\
\hline 6 & 2000 & 160 \\
\hline
\end{tabular}

\section{EFFECT OF VEHICULAR NOISE POLLUTION}

The vehicular noise contributes the most in total noise pollution and its role is very significant in urban areas. The Traffic noise mainly categorize in four broad categories: Airport noise, Railways noise, Vehicular noise and Seaport noise. [Goswami and Swain, 2017] Road traffic noise mainly includes vehicles on the road and streets like car, motorbike, van, truck buses etc. [Prakash and Veerappa, 2015] Vehicle noise includes sources like Engines, Tires interacting with the road, Sound from the motor parts such as gear boxes, cooling fans, brakes etc and Sounds of cooling fans, gearboxes and brakes, flouting traffic rules[Alam,2011]. In addition to vehicle's noise, high traffic density and various commercial activities in suburban area leads to more noise pollution. [Yildiz, 2007]Noise pollution is considered to be an important parameter to ascertain quality of life in cities. Various surveys are carried out at different locations worldwide to assess environmental noise and related analysis [Banerjee et al., 2008]. Study shows that the noise environment of urban cities in India is aggravating and detrimental to human health surpassing standard noise levels. Table 2 depicts the permitted noise level in few countries and World Health Organisation (WHO) standard. To control the noise pollution, noise mitigation must be done but simultaneously we can work to convert induced noise pollution into electrical energy. Noise from the sources mentioned in Table 3 can be transformed into electrical signal using energy harvesting technique. 
Table 2. Acceptable noise level in some countries and World Health Organisation (WHO) standard

\begin{tabular}{|c|c|c|c|c|c|c|c|c|}
\hline \multirow[t]{2}{*}{ Countries } & \multicolumn{2}{|c|}{ Industrial Area } & \multicolumn{2}{|c|}{ Commercial Area } & \multicolumn{2}{|c|}{ Residential Area } & \multicolumn{2}{|c|}{ Silence Zone } \\
\hline & Daytime & Night time & Daytime & Night time & Daytime & Night time & Daytime & Night time \\
\hline WHO & 65 & 65 & 55 & 55 & 55 & 45 & 45 & 35 \\
\hline Australia & 55 & 55 & 55 & 45 & 45 & 35 & 45 & 35 \\
\hline Japan & 60 & 50 & 60 & 50 & 50 & 40 & 45 & 35 \\
\hline US & 70 & 60 & 60 & 50 & 55 & 45 & 45 & 35 \\
\hline India & 75 & 70 & 65 & 55 & 55 & 45 & 50 & 40 \\
\hline
\end{tabular}

Table 3. Sound Power Level of various sources of traffic noise

\begin{tabular}{|c|c|c|}
\hline S. No & Source of traffic noise & Sound Power Level (in dB) \\
\hline 1 & Normal street traffic & 75 \\
\hline 2 & Buses, Trucks, motorcycle & 90 \\
\hline 3 & Heavy city traffic, Heavy diesel vehicle & 92 \\
\hline 4 & cars on highway & 100 \\
\hline
\end{tabular}

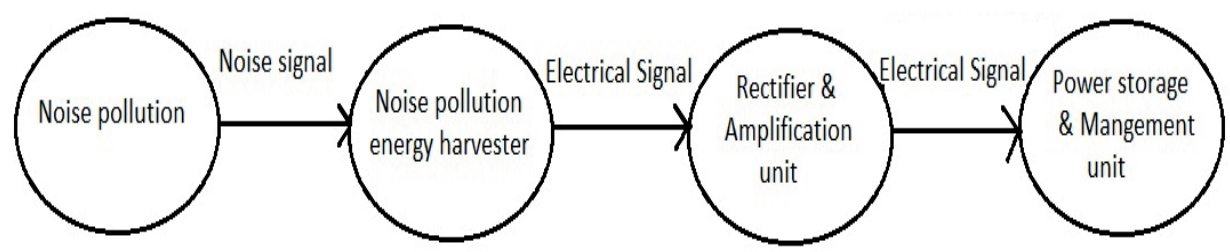

Figure 1. Noise pollution-based energy harvester

\section{METHODOLOGIES}

Figure 1 depicts a simple block diagram of noise pollution-based energy harvester. This energy harvester can transform noise pollution into low level electrical signal. The energy harvester can be based on various principles of energy conversion for acoustic signal such as the principle of electromagnetic induction piezo electricity, MEMS (microelectronic-mechanical system), energy harvester and acoustic meta materials[Gammaitoni, 2012], [Jamal et al., 2013],[Cha et al., 2010]. [Amirtharajah and Chandrakasan, 1998],[Meninger et al.] Piezo electric property exhibited by specific materials has extensive potential to generate clean energy from random sound signal for low power application, reducing the energy consumption to some extent. Super capacitors are used for charge storage as it has very high capacitance value and low voltage limits[Salvador et al., 2017]. It can charge the batteries fast but the cost of super capacitor is very high[Liew et al., 2018]. Micro and nano scale noise harvesting suggests that the kinetic energy of micro level is suitable for energy harvesting. MEMS (microelectronic-mechanical system) technology makes possible to design low power self-recharged devices using MEMS devices as electromechanical transducer which converts in the form of variable capacitor which helps to maximize the response of the system[Cha et al., 2010]. This system has been used for remote sensing applications and low power low maintenance digital signal processing and various other biomedical applications. [Li et al., 2014],[Wischke et al., 2011]. An acoustic meta-material, named HRDM (Helmholtz Resonator with built in Decorated Membrane) found capable of performing dual function of sound insulation and energy harvesting both simultaneously. HRDM can provide better sound insulation and efficient strain energy. Table 4 shows the comparison of various principles that are reviewed in cited papers 
Table 4. Comparative view of various principles of energy harvesting

\begin{tabular}{|c|c|c|c|c|c|}
\hline S. No & Principle & Input applied & Output resulted & Object studied & Applications \\
\hline 1 & $\begin{array}{l}\text { Electro- } \\
\text { magnetic } \\
\text { induction }\end{array}$ & $87 \mathrm{~dB}-90 \mathrm{~dB}$ & $0.6 \mathrm{~V}-1.62 \mathrm{~V}$ & Motor vehicles & $\begin{array}{l}\text { Large scale machines, } \\
\text { power plants }\end{array}$ \\
\hline 2 & $\begin{array}{l}\text { Piezo } \\
\text { electricity }\end{array}$ & $\begin{array}{l}97.6 \mathrm{~dB} \text { (from } \\
78 \text { inch distance) }\end{array}$ & $6.73 \mathrm{~V}$ & $\begin{array}{l}\text { BaTiO3 Piezo } \\
\text { electric transducer }\end{array}$ & $\begin{array}{l}\text { Rechargeable batteries, } \\
\text { Walkway at ticket gate }\end{array}$ \\
\hline 3 & $\begin{array}{l}\text { MEMS } \\
\text { devices }\end{array}$ & $100 \mathrm{~dB}$ & $50 \mathrm{mV}$ & $\begin{array}{l}\mathrm{ZnO} \text { nano wires } \\
\text { electrodes }\end{array}$ & $\begin{array}{l}\text { Self recharged devices, } \\
\text { biomedical application }\end{array}$ \\
\hline 4 & $\begin{array}{l}\text { HRMD based } \\
\text { Meta-material }\end{array}$ & $\begin{array}{l}1 \mathrm{~Pa} \text { (sound } \\
\text { pressure) }\end{array}$ & $\begin{array}{l}244 \mathrm{nW} \text { (with } \\
\text { PVDF) } 3.33 \mu \\
\text { W(with PZT) }\end{array}$ & $\begin{array}{l}\text { Helmholtz } \\
\text { Resonator }\end{array}$ & Low scale devices \\
\hline
\end{tabular}

\section{PROTOTYPE IMPLEMENTATIONS OF SOUND/NOISE ENERGY HARVESTER}

Figure 2 shows a simple one line setup of energy harvesting system. An experimental setup of sound energy harvesting is shown in figure 3[Maruyama, 2020], [Fang et al., 2017]. A wooden box contains loudspeaker and piezoelectric together, providing isolation from atmosphere so that sound signal can be concentrated toward piezo electric. The electrical signal coming through piezo electric after conversion, fed to the CRO, multimeter and SLM (Sound pressure level meter).

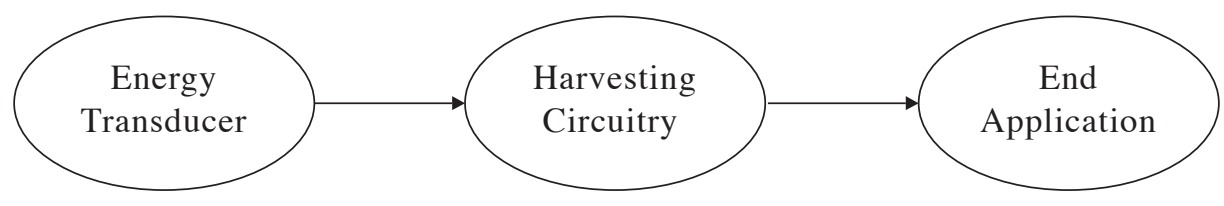

Figure 2. Simple energy harvesting system

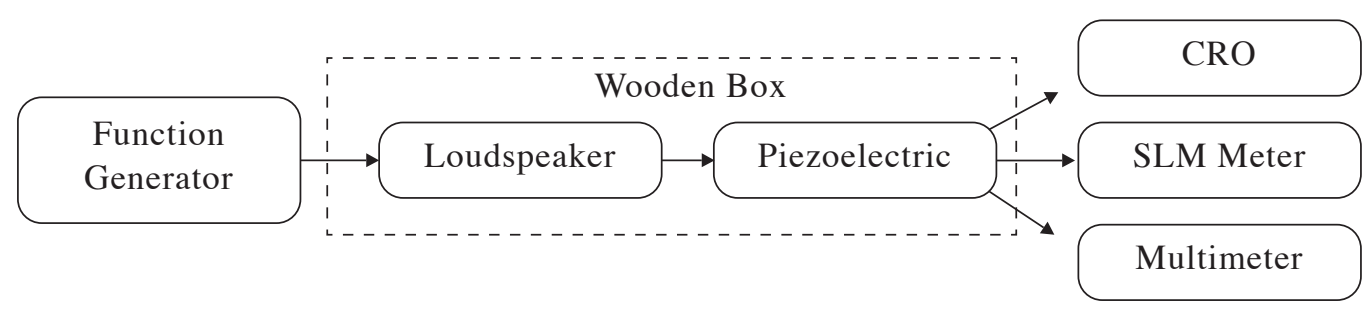

Figure 3. A setup of sound to electrical signal Conversion

A roadway energy harvesting system has been proposed to harvest force exerted on the road due to passing by vehicle's movement is shown in figure 4. Wafer of piezoelectric material are place on the inner layer of the road which converts the exerted pressure into electrical signal then amplified electrical signal further taken to energy management unit by means of electrical wire. Energy storage unit stores the electrical energy that can be further utilized for street lightning purpose. The top layer of the road is made of insulating material provides insulation and safety to the harvester unit place inside[Jiang et al., 2014]. 


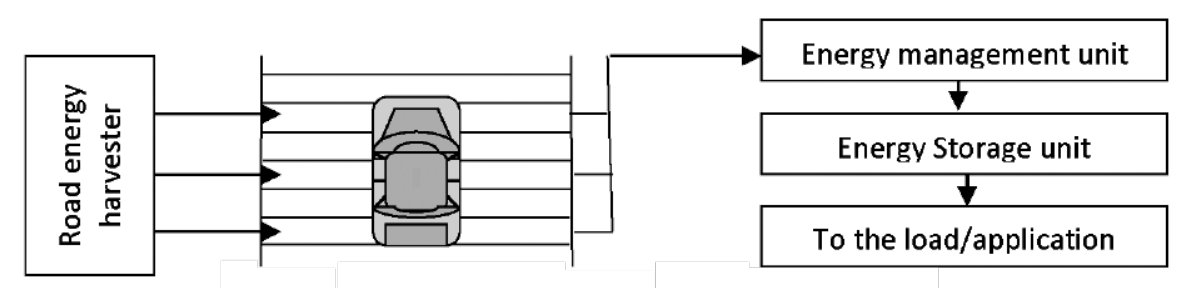

Figure 4. A roadway energy harvesting system

Et. Al Y. Wang proposed a system as shown in Figure 5 and stated that acoustic noise from the high speed train can be converted into electrical signal. AEHU(Acoustic Energy Harvesting Unit) collects the acoustic noise from the passing by trains and converts it in alternating current signal which afterward rectified and get stored in super-capacitor and can be utilized in various applications. The instantaneous output obtained (max.) at $110 \mathrm{~dB}$ sound pressure is $74.6 \mathrm{mV}$ [Wang et al., 2018].

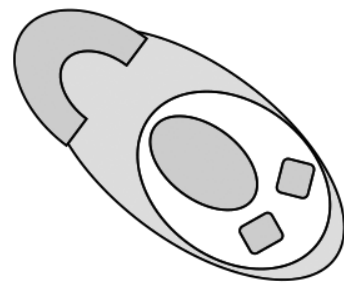

High Speed Train

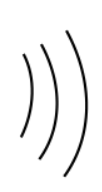

Noise
$\mathbf{A C}$

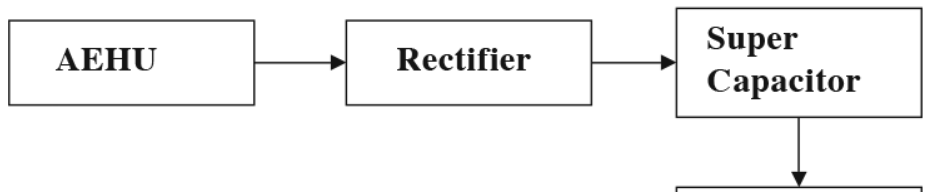

Battery/

load

Figure 5. A noise energy harvesting system for high speed train

\section{NOISE POLLUTION MODELING}

Modeling is basically a method to obtain the relation among various variables involved in anyprocess [Subramani and Sivaraj, 2012]. By the means of noise pollution model, one can find the effect and quality of sound and predict noise impact. In recent years, various models have been used to analyse road traffic noise[Verghese et al., 2013], [Kumar et al., 2011]. In some investigations real time data is also accessed by means of sound level meter, velocity meter, temperature sensor, humidity sensor and many other appliances. A general expression of Sound Pressure Level for noise pollution measurement is shown in Equation (2)

$$
\mathrm{L}_{\mathrm{eq}}=\mathrm{A}+\mathrm{B} \log _{10} \mathrm{~V}
$$

Where $\mathrm{A}$ and $\mathrm{B}$ are constants, and $\mathrm{V}=$ Equivalent number of vehicles moving on the road in an hour. [Bilaşco et al., 2017], [ Sivaraman et al., 2013]A mathematical model was devised to predict sound pressure level using parameters such as type of road, average vehicle's speed, total vehicle volume/hour, ambient and surface temperature and relative humidity. Other important parameters to calculate level of road traffic are type of road- single / double lane, traffic volume, speed of the traffic, and no. of heavy vehicles in traffic flow. Regression, linear regression and multiple linear regression methods are used to analyze the model [Rajakumara and Mahalinge Gowda, 2009] [Kumar and Jain, 1994]. Along with traffic data obtained, land use data has also taken as independent variable to formulate the model using multiple regression method. Validation of model was done by subtracting observed value of noise level from predicted value of noise level, calculating correlation- coefficient and paired t- test for examining Goodness of fit. Calixto model claims that heavy vehicles generate more noise as compared to light vehicles. Regression analysis based on Calixto model gives good R2 values for Indian conditions when compared to the data collected[Calixto et al., 2003] [Kumar et al., 2011]. The advantage and drawback of sound detection techniques is shown in Table. 5 
Table 5. Major advantages and drawbacks of sound detection techniques

\begin{tabular}{|c|c|c|c|}
\hline S. No & Sound detection techniques & Advantages & Drawbacks \\
\hline 1 & Normalized filter technique & Simple, less complex, better performance & $\begin{array}{c}\text { Not suitable for } \\
\text { successive event with } \\
\text { very short intervals }\end{array}$ \\
\hline 2 & Median filter Technique & Suitable for continuous detection & Delayed response \\
\hline 3 & Thresholding & Fast & $\begin{array}{c}\text { Noisy, not suitable } \\
\text { for running background }\end{array}$ \\
\hline 4 & Feature Classification & $\begin{array}{c}\text { Suitable for background noise with } \\
\text { low SNR }\end{array}$ & - \\
\hline
\end{tabular}

All around the Globe, researchers are predicting and determining the noise propagation level in different countries[Steele, 2001]. Federal Highway Administration Traffic Noise Model FHWA is the popular software model for traffic noise calculation used in USA, CoRTN (Calculation of Road- Traffic Noise) in UK, ASJ RTN model in Japan and in Germany RLS 90 standard is mainly used. A solid management is carried out in Karachi where lot of waste is created, in the complete process huge amount of noise is generated, after which utilisation of noise is worked in different applications purposes like electricity, mechanical wear[Shaikh and Hussain, 2019].

\section{OPTIMIZATION PROCEDURE}

When the noise model is developed and parameters of interest are detected then there comes a requirement of the optimization of the variables. A mathematical process to find out minimum or maximum output by modifying system characteristics is known as optimization procedure[Prakash and Veerappa, 2015]. The most common technique for optimization is meta-heuristic optimization used to search optimal solution of the problem[Cammarata et al., 1995]. There are various procedures of finding optimal solutions for example GA (Genetic Algorithm), Particle Swarm Optimization, Ant Colony Optimization, Hill climbing etcetera[Gao et al., 2019]. Genetic algorithm can optimize the linear and non linear problem used for multi objective optimization for various applications generally using initialization, representation, evaluation, selection, genetic operation and termination steps [Rahmani et al., 2011]

Artificial neural network (ANN): It is an effective method to deal with complex-linear and non linear problems on large scale. A single layer recurrent back propagation (levenberg marquardt) algorithm based ANN model is found to give better performance of predicting noise and minimizes mean square error. Et. Al. V. Nourani presented emotional artificial neural network for road traffic noise which was Artificial intelligence based model and it improved efficiency of predicting traffic noise[Nourani et al., 2020].

HFSP (Hybrid Flow shop Scheduling Problem): It is a new technique to improve the production efficiency and consumption of energy. Noise pollution model is a multi objective problem and it can be expressed as in Equation (3)

$$
\operatorname{Min} f(x)=\min \left[f_{1}(x), f_{2}(x), \ldots f_{n}(x)\right]
$$

Where $\mathrm{x}$ is solution vector,Let $\mathrm{p}$ and $\mathrm{q}$ are solution; Solution $\mathrm{p}$ can dominate $\mathrm{q}$ if and only if $\mathrm{fi}(\mathrm{p}) \leq \mathrm{fi}(\mathrm{q})$. Using this technique, energy consumption can be minimized but computational time is more than the meta heuristic method[Fu et al., 2020; Sener and Koltun, 2018]..

ANFIS (Adaptive neuro fuzzy inference system): It can be used for modelling heterogeneous traffic condition. It is fuzzy inference system for adaptive networks. Complex traffic model considering various parameters such as driving behavior, variable traffic flow can be modelled and provide comparatively better results. [KumarArora and Vimal Mosahari, 2012] A hybrid adaptive learning control of non linear systems has been proposed. Modelling of environmental noise is a complex and non linear problem that can be achieved by feature selection method and machine learning regression methods [Zhang and Zhang, 2017] [Zhang et al., 1995]. Type of methods are MLP (multi layer perceptron), SMO (Sequential minimal optimisation), GPR(Gaussian process regression). These methods 
are considered to be very robust to calculate equivalent sound pressure level. Feature selection methods are to be used along data reduction methods and SMO or GPR to provide best results. The predicted value estimates is shown in Equation (4) as follows

$$
\mathrm{y}^{\wedge}=\mathrm{B}^{\wedge}{ }_{0}+\mathrm{B}^{\wedge}{ }_{1} \mathrm{x}_{1}+\mathrm{B}^{\wedge}{ }_{2} \mathrm{x}_{2}+\ldots . \cdot \mathrm{B}^{\wedge}{ }_{\mathrm{n}} \mathrm{x}_{\mathrm{n}}
$$

Where $\mathrm{x}$ is the variable and $\mathrm{B}$ is the constant vector

\section{EXPECTED DESIGN OF OPTIMAL NOISE POLLUTION MOD}

Let the noise pollution is expressed as $f(x)$ as shown in Eq.(5) which is optimally minimum is expressed as

$$
\text { Objective function }=\min \mathrm{f}(\mathrm{x})
$$

The function $\mathrm{f}(\mathrm{x})$ is subject to constraint as shown in Eq.(6) \& (7) with the inequality limits as

$$
\begin{gathered}
\mathrm{ax} 1+\mathrm{bx} 2<\mathrm{c} \\
\mathrm{dx} 1+\mathrm{ex} 2<\mathrm{f} \\
\mathrm{F}(\mathrm{x})=\min \left(\mathrm{f}(\mathrm{x})+\mathrm{ax}_{1}+\mathrm{bx}_{2}-\mathrm{c}_{\text {min }}+\mathrm{dx}_{1}+\mathrm{ex}_{2}-\mathrm{f}_{\text {min }}\right) * \mathrm{C}(\mathrm{x}) \\
\text { where } \mathrm{C}(\mathrm{x})=\mathrm{a} / \mathrm{f}(\mathrm{x})+\mathrm{b} / \mathrm{f}(\mathrm{x})^{2}
\end{gathered}
$$

The expression of electricity generation from noise pollution could be of form shown in Equation (8) which includes the combination of Equation (5), (6) \& (7) also consider the inequality constraint limit in the equations which is shown in Eq.(8).

\section{APPLICATION}

The noise pollution based energy harvester module can be used for charging small batteries, biomedical applications and implantable medical devices such as pacemaker, defibrillator and etc to be implanted inside the human body for diagnosis and treatment of patient which requires rechargeable batteries have might need to be replaced after some time. These implantable units can be self-recharged by itself by the concept of kinetic energy resulted from piezo electric behavior of cardiac and other body parts movement so that the surgery of the patient will not be required for the same. Recently, billboard and sound scrapper have been immerged to help the grid to fulfill the electricity requirement by energy scavenging from the environmental noise pollution. Billboard consists of thousand acoustic sensors which convert urban noise pollution into electricity without being supplemented by city grid for car battery charging and Sound scraper is a modern technology to transform acoustic noise of the urban cities into source of clean energy. The lot of energy efficient solution can be obtained from waste collected from different drainage system \& after that well-defined system can be installed for generation of electricity using IOT \& artificial intelligence techniques

\section{CONCLUSION}

There is a huge potential in noise pollution to generate clean energy. In this paper we have discussed various techniques and methodologies for converting noise pollution into electrical energy. Modelling of noise pollution based energy harvester, analysis methods and optimization procedures are also discussed. Some specific piezo electric material and meta material have potential to harvest acoustic signals efficiently. With the help of suitable rectification, amplification, power management unit and energy storage element this energy can be used for various low power applications. Review of various traffic noise pollution model and optimization techniques are also discussed in this paper. The relevant design mathematics can be used to limit the noise pollution \& new designed empirical formula can be used to get electricity. The optimum electricity conversion from noise pollution can be achieved by using various optimization techniques and intelligent controllers 


\section{REFERENCES}

Agarwal S, Swami BL. 2011. Comprehensive approach for the development of traffic noise prediction model for Jaipur city. Environ Monit Assess 172(1-4):113-120.

Alam W. 2011. GIS based Assessment of Noise Pollution in Guwahati City of Assam , India 2(2):731-740.

Amirtharajah R, Chandrakasan AP. 1998. Self-powered signal processing using vibration-based power generation. IEEE J Solid-State Circuits 33(5):687-695.

Banerjee D, Chakraborty SK, Bhattacharyya S, Gangopadhyay A. 2008. Modeling of road traffic noise in the industrial town of Asansol, India. Transp Res Part D Transp Environ 13(8):539-541.

Bilaşco Ş, Govor C, Roşca S, Vescan I, Filip S, Fodorean I. 2017. GIS model for identifying urban areas vulnerable to noise pollution: case study. Front Earth Sci 11(2):214-228.

Calixto A, Diniz FB, Zannin PHT. 2003. The statistical modeling of road traffic noise in an urban setting. Cities 20(1):23-29.

Cammarata G, Cavalieri S, Fichera A. 1995. A neural network architecture for noise prediction. Neural Networks 8(6):963-973.

Cha SN, Seo JS, Kim SM, Kim HJ, Park YJ, Kim SW, Kim JM. 2010. Sound-driven piezoelectric nanowire-based nanogenerators. Adv Mater 22(42):4726-4730.

Chauhan A, Pawar M, Kumar D, Kumar N, Kumar R. 2010. Assessment of Noise Level Status in Different Areas of Moradabad City. Researcher 2(5):88-90.

Fang LH, Hassan SIS, Rahim RA, Isa M, Ismail B Bin. 2017. Charaterization of Differents Dimension Piezoelectric Transducer for Sound Wave Energy Harvesting. Energy Procedia 105:836-843.

Farghaly YA, Hemeida FAA, Salah S. 2019. Noise utilization as an approach for reducing energy consumption in street lighting. PLoS One 14(7):1-20.

Fu, Y. Li, Z. Chen, N. and Qu, C. 2020. A Discrete Multi-Objective Rider Optimization Algorithm for Hybrid Flowshop Scheduling Problem Considering Makespan, Noise and Dust Pollution, IEEE Access.

Gammaitoni L. 2012. There's plenty of energy at the bottom (micro and nano scale nonlinear noise harvesting). Contemp Phys 53(2):119-135.

Gao, K. Cao, Z. Zhang L. Chen, Z. Han, Y. and Pan, Q. 2019. A review on swarm intelligence and evolutionary algorithms for solving flexible job shop scheduling problems, IEEE/CAA J. Automatica Sinica, vol. 6, no. 4, pp. 904-916.

Goswami S, Swain BK. 2017. Environmental Noise in India: a Review. Curr Pollut Reports 3(3):220-229.

Jamal GRA, Hassan H, Das A, Ferdous J, Lisa SA. 2013. Generation of usable electric power from available random sound energy. 2013 Int Conf Informatics, Electron Vision, ICIEV 2013 (October 2015). https:// doi.org/10.1109/ICIEV.2013.6572549.

Jiang X, Li Y, Li J, Wang J, Yao J. 2014. Piezoelectric energy harvesting from traffic-induced pavement vibrations. J Renew Sustain Energy 6(4):1-16.

Kjellberg A, Tesarz M, Holmberg K, Landström U. 1997. Evaluation of frequency-weighted sound level measurements for prediction of low-frequency noise annoyance. Environ Int 23(4):519-527.

Kumar D, Kumar D. 2018. Abatement of Noise Pollution. Sustain Manag Coal Prep 279-291. 
Kumar K, Jain VK. 1994. A study of noise in various modes of transport in Delhi. Appl Acoust 43(1):57-65. Kumar K, Katiyar VK, Parida M, Rawat K. 2011. Mathematical modeling of road traffic noise prediction. Int J Appl Math Mech 7(4):21-28

KumarArora J, Vimal Mosahari P. 2012. Artificial Neural Network Modelling of Traffic Noise in Agra-Firozabad Highway. Int J Comput Appl 56(2):6-10.

Li H, Tian C, Deng ZD. 2014. Energy harvesting from low frequency applications using piezoelectric materials. Appl Phys Rev 1(4).

Liew HF, Rahim RA, Isa M, Ismail B, Hassan SIS. 2018. Analysis of batteries or supercapacitor as energy storage device for a sound energy harvester system. IEEJ Trans Electr Electron Eng 13(12):1699-1708.

Maruyama M. 2020. Dynamic properties of peak levels of road traffic noise along a freeway. Appl Acoust 160:107095.

Meninger S, Mur-miranda JO, Amirtharajah R. Vibration-to-Electric Energy Conversion 48-53.

Nguyen TD, Khan JY, Ngo DT. 2017. Energy harvested roadside IEEE 802.15.4 wireless sensor networks for IoT applications. Ad Hoc Networks 56:109-121.

Nourani V, Gokçekuş H, Umar IK, Najafi H. 2020. An emotional artificial neural network for prediction of vehicular traffic noise. Sci Total Environ 707:136134.

Peckens C, Porter C, Rink T. 2018. Wireless sensor networks for long-term monitoring of urban noise. Sensors (Switzerland) 18(9).

Prakash TN, Veerappa BN. 2015. Interpretation of noise pollution effects on human being using fuzzy logic techniques. Int J Comput Sci Mob Comput 4(4):670-683.

Rahmani S, Mousavi SM, Kamali MJ. 2011. Modeling of road-traffic noise with the use of genetic algorithm. Appl Soft Comput J 11(1):1008-1013.

Rajakumara HN, Mahalinge Gowda RM. 2009. Road traffic noise prediction model under interrupted traffic flow condition. Environ Model Assess 14(2):251-257.

Salvador CS, Abas MCA, Teresa JA, Castillo M, Dimaano K, Velasco CL, Sangalang J. 2017. Development of a traffic noise energy harvesting standalone system using piezoelectric transducers and super-capacitor. Proc -25 th Int Conf Syst Eng ICSEng 2017 2017-Janua:370-376.

Sener O, Koltun V. 2018. Multi-task learning as multi-objective optimization. Adv Neural Inf Process Syst 2018-December(NeurIPS):527-538.

Shaikh, A. Hussain,M.A. \& Baig, M.M.2019. A novel Mathematical Model for Solid Waste Management for Urban Area: Case study for District Malir, Karachi,International Conference on Computing, Mathematics and Engineering Technologies.

Sivaraman S, Morris B, Trivedi M. 2013. Observing On-Road Vehicle Behavior: Issues , Approaches , and Perspectives (Itsc):1772-1777.

Steele C. 2001. Critical review of some traffic noise prediction models. Appl Acoust 62(3):271-287

Subramani T, Sivaraj MKKP. 2012. Modelling of Traffic Noise Pollution. Int J Eng Res Appl 2(3):3175-3182

Torija AJ, Ruiz DP. 2015. A general procedure to generate models for urban environmental-noise pollution using feature selection and machine learning methods. Sci Total Environ 505:680-693.

Verghese V, Subramanian SC, Vanajakshi L. 2013. Model based Traffic Control in Indian Conditions. Procedia - Soc Behav Sci 104:516-525 
Wang Y, Zhu X, Zhang T, Bano S, Pan H, Qi L, Zhang Z, Yuan Y. 2018. A renewable low-frequency acoustic energy harvesting noise barrier for high-speed railways using a Helmholtz resonator and a PVDF film. Appl Energy 230(July):52-61.

Wischke M, Masur M, Kröner M, Woias P. 2011. Vibration harvesting in traffic tunnels to power wireless sensor nodes. Smart Mater Struct 20(8).

Yildiz F. 2007. Potential Ambient Energy-Harvesting Sources and. Energy 40-48.

Zhang P, Sankai Y, Ohta M. 1995. Hybrid adaptive learning control of nonlinear system. Proc Am Control Conf 4(June):2744-2748.

Zhang XZ, Zhang GJ. 2017. Numerical optimization of sound pressure responses for the dash panel based on automatically matched layer and genetic algorithm. J Vibroengineering 19(4):3040-3055. 